\title{
ASPECTOS DE UNA DIALÉCTICA ESPECULARIA EN UNA LUZ MUY LEJANA DE DANIEL MOYANO
}

\author{
POR \\ Catharina de Vallejo \\ Concordia University, Montreal
}

A primera vista, un enfoque arquetípico - utilizando por ejemplo los conceptos de Eliade y de Jung - parecería constituir la vía más apropiada para sondear la dimensión significativa de Una luz muy lejana del escritor argentino Daniel Moyano. ${ }^{1}$ Se evidencian muchos elementos que permiten la postulación de un conjunto estructural de carácter mítico, como lo son la circularidad, la atemporalidad y el paradigma de la aventura iniciática de un personaje —el protagonista Ismael- que puede verse como un 'héroe' mítico. ${ }^{2}$ Muchos signos narrativos sugieren arquetipos de interpretación simbólica, como por ejemplo, el pozo, la(s) puerta(s), el cordero, el árbol, y la presencia de diferentes aspectos de la feminidad. Los nombres de algunos de los personajes también cobran valor simbólico de arraigo bíblico, mitológico o literario: Ismael, Marta, Jacinto, y Beatriz. Por último, el cuento infantil insertado a lo largo de la novela funciona como paradigma que remite a dimensiones arquetípicas. Este cuento, recordado episódicamente por Ismael, estructura la narrativa de forma especularia, y así proporciona un punto de partida para un enfoque diferente de investigación, un enfoque doble que permite enriquecer la interpretación de la obra, desde las perspectivas complementarias de la mise en abyme y del psicoanálisis.

Una luz muy lejana ha sido calificada como novela 'episódica' Barufaldi opina que la obra "obedece a la técnica cuentística de los relatos ligados", lo que produce un "desajuste" (25) en su estructura. Sin embargo, más que episódica, se presenta una fragmentación de la forma novelesca como reflejo del reconocimiento primario del ser en tanto unidad existencial independiente, reconocimiento que constituye lo que Jacques Lacan ha elaborado en su concepto de la "fase del espejo" del desarrollo humano entre los seis meses y los dos años y medio de la vida (Écrits 93-100). Se trata de un proceso de auto-identificación,

\footnotetext{
${ }^{1}$ Ha sido su primera novela, publicada en 1966. Citaremos por la edición de la Editorial Sudamericana, Buenos Aires, 1966.

${ }^{2}$ Según conceptos de Joseph Campbell (1949) en esta novela el itinerario heroico se establecería de la siguiente manera: salida [aquí: "Entrada" a la ciudad, siendo Ismael niño], llamada a la aventura [de la iniciación a la madurez], pasar el umbral [mudanza al patio], iniciación [relaciones sexuales], las pruebas [participación activa en las decisiones], la mujer como sirena [Marta-Beatriz], reconciliación con el padre [viaje con Jacinto], vuelta [aquí: "Salida" de la infancia y comienzo de la vida de adulto en la ciudad]. Ver también el trabajo de Clinton sobre la búsqueda y el de Curutchet sobre el mito de la adolescencia.
} 
proceso en el que el 'yo' adquiere un matiz simbólico primordial cuya imagen reflejada se configura en calidad de ideal (Lacan 94). La forma total del cuerpo del individuo - niñole es dada como una exterioridad desde la imagen reflejada en el espejo. El sujeto mira elementos aislados de su reflexión para poder construir, desde ese cuerpo despedazado o fragmentado, su totalidad como individuo.

Lucien Dallenbach, en su obra dedicada a la narrativa especularia, se muestra consciente de la posible relación entre este concepto y la fase del espejo:

On est invité à rapprocher ce dédoublement narcissique de l'expression originaire que $\mathbf{J}$. Lacan distingue sous le nom de "stade" ou "phase du miroir" ... (26) ... le miroir des premières années réactualisant l'intégration inaugurale du corps y du language ... en un scénario ... de réappropriation (27).

En Una luz muy lejana integra precisamente el desarrollo de un ser humano correspondiente a la fase del espejo, mediante una estructura narrativa y un texto que se configuran como mise en abyme. El espacio entre los elementos reflejados - ser e imagen, realidad e ideal- constituye una dialéctica en la que el texto expresa la apropiación del mundo, del lenguaje y del propio ser por parte del protagonista.

[Ismael] [h]abía salido de un pueblo que, en rigor, no recordaba, quizás porque voluntariamente lo había olvidado. Sólo sabía o quería saber que allá todo era mejor, más fácil, más cálido, como si hubiese una termperatura permanente. Pero en medio de la oscuridad total que aquel olvido suponía, había como una visión o presentimiento absoluto de las cosas. Y todo aquello, irremediablemente perdido, se borró para siempre cuando él entró en la ciudad .... (Una luz muy lejana 18)

La llegada de Ismael a la ciudad se presenta como un nacimiento, y sus primeros meses en la ciudad equivaldrían a los primeros meses de vida de un recién nacido. Ismael no conoce a nadie, sus acciones tienen la torpeza de uno que no sabe cómo hacer las cosas, y es incapaz de hacer decisiones. Durante esos primeros meses vive gratis en una habitación de la casa de una familia que "lo ignoraba totalmente" (19); "no conocía a nadie, la gente era reacia a la amistad, y ... todo era nuevo para él" (19); no tiene comunicación con la familia (20). El proceso de auto-reconocimiento de Ismael comienza cuando se muda al patio con las puertas y el pozo, donde conoce a los seres que servirán - cada uno de ellos de su propia forma - de reflexión de algún aspecto o fragmento de su ser. Así, el espacio narrativo de los capítulos "La pareja", "Marta", "Flaca", "Reartes", "Mensaque", "Endrizi", "Teodoro", "Lucas", y "El pozo", consiste muy específicamente en ese espacio dialéctico que se instituye entre Ismael y los otros personajes.

Como es el caso con muchos 'cuentos infantiles', el de Ismael opera su paradigma significativo desde el nivel de una fábula concreta: un hombre emprende un viaje, rodando mundo, hasta ver una casa con una ventana iluminada donde quiere llegar para comunicarse con los habitantes. Ismael, de forma inversa - es decir, especularia- concibe este cuento como paradigma o ideal, como un segundo nivel de conciencia, aplicándolo a su vida concreta. De esta manéra, en cada referencia hecha al cuento se presenta un movimiento dialéctico entre la circunstancia concreta de Ismael y el fragmento del cuento, movimiento 
que verifica la autenticidad de la experiencia vital de Ismael con respecto a la experiencia narrada en el cuento. El proceso por el que pasa Ismael puede representarse de la siguiente forma:

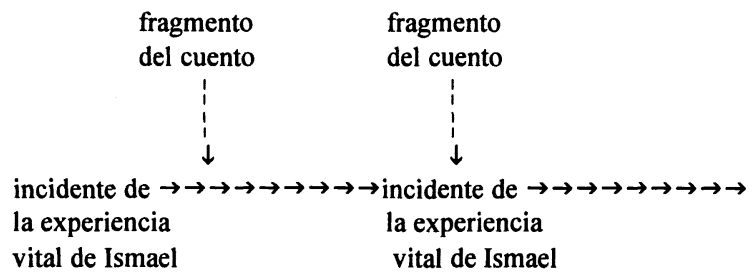

Se trata de un proceso psicológico en el desarrollo del niño que, en su aprendizaje cognitivo sobre el mundo, reconoce lo abstracto desde lo concreto, proceso que se va modificando e invirtiendo con la experiencia (Freedman \& Kaplan 158).

La mise en abyme es definida por Lucien Dallenbach como "toute enclave entretenant une relation de similitude avec l'oeuvre qui la contient" (18), y puede tener diferentes formas y existir en diferentes niveles de la estructura narrativa. Al rasgo de una 'similitud' como eje de la reflexión especularia narrativa, habrá que añadir el de la inversión: el espejo invierte cuanto refleja, de modo que se produce "un rapport de symmétrie inverse" (Dallenbach 67). Esta calidad resulta clave para la novela de Moyano, en la que no sólo hay similitud, sino que también -y sobre todo- hay oposición, inversión de lo reflejado. La distancia que mide entre el objeto y su reflexión constituye un espacio dialéctico que permite la búsqueda de la conciliación entre los opuestos.

Varias de las formas elementales de la mise en abyme - utilizando los términos de Dallenbach- están presentes en Una luz muy lejana. El cuento infantil de la novela se clasificaría, en un primer momento, como una mise en abyme "del enunciado" o "ficcional"; es decir que refleja la fábula del relato. Dallenbach explicita que este tipo de puesta en abismo literaria conforma dos operaciones distintas: por un lado, se trata de una repetición en miniatura de esta fábula - una réduction; por otro, esa repetición provee una elaboración del paradigma de referencia (Dallenbach 77). Citemos los primeros cuatro fragmentos del cuento infantil de la novela, contenidos todos en el segundo capítulo, titulado "Una luz muy lejana", el que sirve de introducción general a la fábula; aparecerán las citas en su contexto sintagmático:

[1] Entonces, cuando salió a rodar tierra, caminó y caminó, caminó mucho, día y noche, hasta que al fin vio una gran luz. Era la luz que salia por una ventana y pensó que allí había gente y que podría hablar, decir que habia salido a rodar tierra y que eso estaba haciendo.

De esta manera se representaban en su mente los relatos oídos en la infancia; y si entonces le pareció más fácil aquello, ahora se daba cuenta con cierta tristeza de que no era así y que los sucesos no salían a su alcance con tanta espontaneidad sino que él debía ser parte de los mismos, hablar y explicarse a través de tanto mundo ... pero sin saber qué hacer (11-12). 
[2]

Caminó muchos días y muchas noches hasta llegar a la casa desde donde había salido la luz. Llamó a la puerta y nadie contestó. Cuando abrió vio adentro a una viejecita que tiritaba de frío sobre una silla, y que le dijo: "ay, ay, soy una pobre mujer ciega y necesito que me ayuden".

No. El bar donde trabajaba no era, en modo alguno, como la casa hallada en el cuento. Sin duda allí el relato se equivocaba, algún error había habido ....(16).

[3] La viejecitale dijo que siguiese caminando durante varios dias y varias noches y que al llegar al cruce de dos caminos deseara tres cosas y tomara por el que viera primero.

El hubiera salvado los deseos, porque no sabía concretamente todavía qué se proponia ... (18).

[4] ... se decidiría sobre alguna de las dos proposiciones.

Caminando y caminando vas a llegar a un lugar donde el camino se divide en dos. Alli desearás tres cosas, las más hermosas, y tomarás por el camino que hayas visto primero, dijo la viejecita (29).

En estas primeras instancias del cuento infantil se presenta un distanciamiento neto diferenciación tipográfica y sintáctica - entre la dimensión del cuento y la de la realidad de Ismael. El movimiento dialéctico, asimismo, es aparente a primera vista; el fragmento del cuento surge en la mente de Ismael sin advertencia, pero de una vez lo relaciona, lo compara, con su propia vida. La cuarta citación es una repetición de la tercera, porque Ismael no se ha dado cuenta de que ya ha tomado por el camino que "ha visto primero" al aceptar la invitación de Eusebio para ir con él a la fiesta de Año Nuevo. ${ }^{3}$ Después de esa cuarta citación y la fiesta de Año Nuevo comienza el viaje de Ismael por "el camino que ha visto primero", la mudanza al patio y la relación con los varios personajes reflejos de aspectos de su propio yo.

En esa aventura ocurren varios episodios claves que se pueden relacionar con la dialéctica especularia, tanto en su aspecto de texto - mise en abyme literaria-como en el psicoanalítico - la 'fase del espejo'. El comienzo de la trayectoria psicológica tiene a Ismael como ser que no distingue el 'yo' como distinto del 'otro', ni tampoco se reconoce como 'yo-hombre' —distinto de la mujer.

Como es de esperar en un ser humano que pasa por esa etapa temprana de autorreconocimiento, las relaciones humanas primarias de Ismael se concretizan en lo femenino, sin hacer distinción entre los aspectos de maternidad y sexualidad de la mujer. Ismael se da cuenta desde su llegada al patio —en el capítulo "La pareja" - de una dimensión vital escondida, secreta y misteriosa, y poco a poco descubre que es la dimensión sexual. La relación que llega a tener con Marta - una muchacha con las piernas deformadas - es una relación sexual, pero lo que Ismael primero y principalmente busca y ve en ella es la imagen de la madre. Confunde a su madre con su amante:

\footnotetext{
${ }^{3}$ Es notable (¿coincidencia?) que en uno de sus artículos Lacan ofrece el siguiente ejemplo de la comunicación que define la subjetividad, la que así hace con referencia al 'otro': "Tu iras par ici, et quand tu verras ceci, tu prendra par la" (298, artículo de 1953).
} 
Después [del acto sexual] soñó con la madre, pero no podía verla. No sabía cómo era. Su madre le decía que se había equivocado, que aquello no se hacía así. Debía seguir las instrucciones de Marta. La madre estaba de espaldas ..., era siempre una espalda desnuda lo que percibía, como si jamás hubiese tenido rostro. Y él procuraba saber también cómo eran las piernas de su madre, saber si eran como las de Marta, pero no se animaba por temor de que fuesen idénticas. Finalmente dio un salto y la tocó. La cintura era como la de Marta, y el pecho también. De este seno mamaste, creyó oír que le decía la madre ... (57-58).

Así, Marta constituye al mismo tiempo el paradigma de la mujer amante (sexualidad) y el arquetipo de la madre (maternidad), en un nivel de conciencia abstracta y universal:

-Marta - dijo después [de tener relaciones sexuales con ella].

-Sí.

-No sé de dónde saliste. No sé nada más que tu nombre.

Ella sonrio.

—Vengo de una madre — dijo—, y de otra, y de otra más, y de muchas más.

-Yo también - dijo él, ...

- No - afirmó ella - Venís de un padre, y de otro, y de miles de padres. Nosotros, anoche, hemos juntado los padres con las madres (59).

Paradójicamente, es cuando los dos aspectos de lo femenino se materializan y se funden en una persona (Marta espera un hijo), que Ismael está forzado a hacer la distinción, ante lo que se le revela. El embarazo impulsa en Ismael y en Marta la necesidad de una decisión acerca del futuro hijo. Este acontecimiento ocurre en el centro de la novela - en el capítulo titulado "La avenida arbolada" - y constituye un primer momento de crisis consciente para Ismael. Marta pide que éste le acompañe al consultorio del médico donde le provocarán un aborto, pero Ismael se siente incapaz de tal acción. Abandona a Marta no totalmente consciente de su cobardía - quedándose indeciso en su habitación. Esa pasividad es típica del niño muy joven que, simplemente, no es capaz de tomar decisiones. Ismael se percata de esta actitud, la “... maldita costumbre que tenía de aceptar todo tal como venía ..." (93). Al mismo tiempo, brota el cuento infantil en su conciencia, ahora como razonamiento existencial directa y concretamente relacionado con su circunstancia:

... cuando alguna vez le contaron historias de alguien que salía y andaba y caminaba durante días y noches interminables para llegar a tal o cual parte, se decía con claridad adónde se llegaba. Era eso y no otra cosa. En la pieza iluminada que se divisaba desde mil leguas y donde brillaba una luz, una vieja decía que estaba ciega y que no podía seguir andando. El tampoco siguió andando, como si hubiese quedado ciego. Marta volvería más tarde por mil regiones oscuras.

... Tenía que irse de allí y olvidar todo. ... empezar de nuevo ... Entonces se abrirían nuevos caminos y podría llegar muy lejos. Llegar hasta la luz. Pero en los relatos aquellos no estaba Marta, jamás la había entrevisto en sus recuerdos, de modo que ella tenía que quedarse allí (91).

Se nota aquí que el texto del cuento forma parte del (con)texto de la fábula principal: no queda separado tipográficamente ni sintácticamente. También se nota que Ismael 
presiente la separación —diferenciación—que tendrá lugar entre sí mismo (yo-hijo) y Marta (otro-madre/amante). Concibirá la femenidad como diferenciada en aspectos que distinguirán la maternidad de las otras facetas femeninas.

Después de este episodio conoce a la hija de Endrizi (en el capítulo que lleva el mismo título), llamada Beatriz, de cuya belleza se enamora, observándola a través de un espacio insuperable de clase, de circunstancia y de sexo:

La blancura de los hombros de Beatriz esplendía hacia un costado .... su rostro era lo más puro de este mundo (129). ... Sentía que Beatriz significaba algo que él había presentido alguna vez, algo hermoso y verdadero que explicaba los misterios y los padecimientos. ... Pero sintió también que entre él y ella había ... cosas: ...Beatriz era algo vedado porque no podía asociarse lo que ella representaba, con su pasado, con sus frustraciones, con Marta, con Teodoro, con el perro en el aljibe, con el consultorio del médico ...(130).

Es patente que Ismael ha tomado conciencia de (la falta de) sus acciones hacia Marta y las concibe como negativas. Al mismo tiempo se percata de otras posibles relaciones con mujeres. Beatriz se instituye para Ismael en la mujer ideal, como belleza inalcanzable y como pureza vedada para él por siempre. Con el tiempo, él asimilará el recuerdo de Beatriz, no como una muchacha concreta y particular, sino como concepto, como una imagen: "Beatriz".

Cuando se presenta otro problema relacionado con el ideal femenino, Ismael se encuentra capaz de encontrar alguna solución, tomar una decisión que es de alguna forma más positiva. Este episodio trata de una muchacha admirada y amada desde lejos por Teodoro, el carpintero pseudo-intelectual que también vive en el patio donde reside Ismael. Teodoro le pide a Ismael que éste le dé una carta a la muchacha -que Teodoro dice llamarse Lita-, y ocurre una conversación entre Ismael y la muchacha - que "en realidad se llamaba Rosa" (145). En esta conversación Ismael le cuenta los sentimientos de Teodoro a la muchacha, y ésta trata de desanimar esos sentimientos, casi burlándose. Le preocupa a Ismael tener que decirle a Teodoro lo sucedido: no quiere mentir, precisamente, pero tampoco quiere herir a su amigo. Invierte, entonces, la conversación que tuvo con LitaRosa, para que queden en la boca de él las cosas que había dicho ella, y en la de ella lo que había dicho él:

Conversación Ismael-Lita(Rosa)

—Todo esto — dijo ella, ...

es tremendamente absurdo (148).

-Lo que él quiere, lo que él desea - dijo Ismael- es que usted lo ame (149).

- Lo comprendo - dijo ella. Pero no es un amor normal, como el que une a un hombre con una mujer (149). y lo relatado a Teodoro por $I$.

- Le dije que todo eso me parecía absurdo (154).

-Dijo [ella] que lo único que Usted quería era que ella lo amase...(154).

-Entonces yo le dije que quizás eso no fuese normal ... (154). 
-Yo creo - dijo Ismael- que

es un hombre bueno, $y$ creo también que merece que lo quieran (149).
-Me dijo que usted era un hombre bueno y que se merecía que lo amasen (154). etc. ${ }^{4}$

El lenguaje es el modo primario de comunicación del ser humano, y comunicarse con otros seres humanos había sido el fin primario del viaje emprendido por el hombre modelo de Ismael - en el primer fragmento del cuento infantil. Ismael ha podido establecer comunicación, pero en sentido inverso: la conversación queda puesta al revés, ya que ha vuelto a sí mismo. Lacan explicita, en efecto, que la comunicación se establece en la medida en la que el emisor vuelve a recibir del receptor su propio mensaje, invertido (298) en el trayecto dialéctico entre el 'yo' y el 'otro'. En el ejemplo citado se descubre además una doble inversión: Teodoro recibe el mensaje de la muchacha al revés, e Ismael infunde en el incidente de Lita-Rosa sus propios sentimientos hacia Beatriz. Por ejemplo, Lita-Rosa tenía "una sonrisa parecida a la de Beatriz" (148); también inventa Ismael "un vestido blanco, ... bastante largo" (153) para Lita-Rosa - vestido que es recuerdo de Beatriz. La comunicación entre los (dos) seres humanos también se establece, de esta forma, como espacio dialéctico donde se permite la búsqueda de conciliación.

Al haber tomado la decisión de traicionar al amigo por no herirle, Ismael al mismo tiempo

sentía que había perdido al amigo, y, con él, uno de los pocos asideros con que contaba para entender todo lo que estaba viviendo. Desde ahora se sentía más desvalido, ante una realidad que apenas entendía, más solo ante las personas y las cosas, como cuando acababa de llegar a la ciudad ... (152).

Nuevamente ocurre, en el reconocimiento de la acción, la conciencia de la separación que tiene que sufrir, frente al mundo, el 'yo' como ser autónomo. El lenguaje, articulación del conocimiento humano (Lacan 298), capacita a Ismael para establecer esa distancia. El lenguaje humano deriva del reconocimiento de la realidad del 'otro', y esa calidad define la misma subjetividad en tanto captación del yo. El dominio - adquisición- del lenguaje adecuado y apropiado le permite a Ismael distinguir la solución al problema con respecto a Teodoro y a sus propias emociones.

El último episodio de interés con respecto a lo femenino es el de la Flaca, narrado en el capítulo titulado "El pozo" - estructuralmente reflejo del capítulo "La pareja". El pozo es elemento de la fábula en cuanto se encuentra en el patio donde vive Ismael; en este capítulo se constituye en símbolo de la perversión más absoluta a la que puede llegar el ser humano en tanto hombre y mujer. ${ }^{5}$ Acompañado de algunos conocidos del patio, Ismael sale en busca de "una mina"; los hombres urgen a un muchacho a tener relaciones sexuales con

\footnotetext{
${ }^{4}$ Una vez antes Ismael había tenido que reportar una conversación a otro: en "La pareja" Ismael le cuenta a Teresa lo que había dicho - sobre ella - Tomás. Se trata de aspectos evidentemente sexuales que Ismael no entiende bien todavía, y cuenta los detalles directamente y sin escrúpulo.

${ }^{5}$ Curutchet opina que el pozo refiere a la ciudad como fuente de lo pervertido, de los valores más negativos de la cultura humana.
} 
la mujer. Al darse cuenta de que la mujer es "-La madre, infeliz - dijo uno de los Chacones” (178), irrumpe en Ismael un fragmento del cuento de la infancia - presentado en letras bastardillas y entre paréntesis:

(Y llegó finalmente, después de mil dias y mil noches, a la casa donde habia divisado la luz. Alli un hombre muy viejo le dijo: poco puedo ayudarte, hijo mio, pero debes seguir; yo también caminé miles de dias y de noches, pero ya estoy muy viejo y no puedo ayudarte; he tenido que quedarme aqui. ¿Ves aquella luz, tan lejos? Allá tienes que llegar) (178-179; énfasis nuestro).

En el contexto sintagmático del relato falta una explicitación consciente por parte de Ismael para relacionar el cuento con el momento concreto de su vida. Ocurre una revelación de su 'yo' relacionado con lo masculino - el hombre de la casa lejana-como distinto de lo femenino. Al mismo tiempo descubre el punto de la perversión de la que es capaz la masculinidad y la femenidad. Nadie puede ayudarle a resolver esas situaciones límites, las que no ofrecen nunca un final absoluto; Ismael tendrá que continuar siempre, y siempre solo.

Este momento constituye, pues, como "La avenida arbolada", otro punto clave de la experiencia de aprendizaje de Ismael. En los gritos de la mujer prostituta, Ismael reconoce la voz de la Flaca, una mujer quien con sus dos hijos vive en el patio donde Ismael tiene su habitación. La Flaca era la primera persona en vivir allí, tenía la puerta más bonita y sabía cantar ópera - calidad ésta que ha conmovido a Ismael sobremanera cuando alguna vez la oyó. Ha sido en la belleza femenina y en la música donde Ismael ha podido (entre)ver una posibilidad de algo "hermoso y verdadero" (130). ${ }^{6}$ La Flaca resulta, así, la perversión de todo lo femenino: como amante (sexualidad), como mujer-belleza (ideal transcendente), y como madre. Ismael había concebido siempre la "casa donde había divisado la luz" como un ideal por alcanzar; ahora, de forma inversa, esa meta se materializa en una experiencia de óptima perversión.

Se ha podido ver en el cuento infantil un reflejo de la trayectoria de Ismael en síntesis, proveyendo en el nivel paradigmático los puntos de soporte para los acontecimientos concretos de su existencia, sobre todo lo relacionado con lo femenino. Esta trayectoria se completa en el penúltimo capítulo, "Regresos", que cuenta el viaje de Ismael con Jacinto al pueblo de éste. Ismael le acompaña porque se da cuenta de que el cuento infantil queda relacionado directamente con su vida:

[7] Cómo había pasado el tiempo. Había andado mucho, sin llegar a ninguna parte. Había estado siempre dando vueltas alrededor de las mismas cosas, describiendo un círculo cerrado. Habría que torcer el rumbo, llegar a uno de los lugares presentidos en aquellos relatos que oyó alguna vez en su infancia. Llegar a la ventana donde estaba la luz (183).

En el tren que los llevará al pueblo de Jacinto, Ismael se da cuenta igualmente de que en ese viaje "estaba volviendo hacia un origen" (185), un origen que Ismael había ignorado en el proceso de la fragmentada (re)construcción de sí mismo. Para (re)conocerse, necesita

${ }^{6}$ También "el cornetín de don Reartes ... era una cosa verdaderamente hermosa" (75). 
asimismo (re)construir(se) un pasado, un lugar de nacimiento, y el viaje al pueblo de Jacinto le provee la oportunidad:

Me parece haber estado alguna vez aquí - pensaba—. No sé en qué tiempo pudo ocurrir. ... Estas casas las he visto en alguna parte. En aquellas ruinas me parece haber nacido. Uno puede elegir después de todo el lugar de su nacimiento, porque nadie se acuerda del momento ni del lugar donde nació ... (189).

En eso le viene a la memoria el cuento infantil, que aparece en la mente como reflejo de la conversación que una vez tuvo con Marta acerca de sus orígenes (ver lo citado anteriormente):

[8] La viejecita decía dentro de la memoria: Hace mucho, pero muchísimos años, había un hombre que salió a rodar tierra por el mundo.

-No necesito saber nada del mundo; quiero saber adónde estaba el hombre antes de salir.

-Esa es una pregunta muy difícil, hijo mío, que te llevaría años comprender. ...

-Yo quiero saber adónde estaba antes de salir.

- Supongo, ya que quieres saberlo, que estabas en el vientre de tu madre.

- Quiero saber de antes de eso.

- Supongo, entonces, que en el aire, en las nubes, en el sol, en el pan, en el agua, en todas esas partes. Nadie lo sabe.

-Sí, hay alguien que lo sabe. Marta lo sabía. Ella sabía todas estas cosas, más que usted y más que nadie. Ella no estaba ciega como usted y sabía hacer las cosas. Ahora váyase de aquí. Déjeme en paz. No quiero saber nada (190).

Aquí Ismael ha entrado directamente en el cuento, sintetizándolo con su propia vida. Niega las fórmulas tradicionales - rituales - de los relatos infantiles, para interrogarlos e inquirir acerca del mundo que prometen. Se ha hecho consciente del desfase que existe entre ese mundo y el suyo, y contradice a la viejecita del cuento para instituir a Marta - persona real para él - en el lugar de la experiencia vital. Al separar el mundo del cuento y su propio mundo - cosa que paradójicamente lleva a cabo mediante la síntesis del recuerdo y de la experiencia-, se establece como separado del círculo femenino-maternal para incorporarse a la existencia masculina. La presencia del 'hombre viejo' en el sexto fragmento del cuento infantil ya prefiguraba lo que el viaje con Jacinto confirma con respecto a ese estatuto masculino. Jacinto dice no saber nada de su madre, e insiste en la línea paterna:

- ¿Mi madre? Eso no lo tengo bien claro. Yo soy de aquí, de este pueblo, y él es mi padre. Eso puedo decirte (191).

Ismael trata de ubicar a su propia madre en el sitio apropiado de su recuerdo, de su ser - e inevitablemente la coloca con Marta, mujer que hizo de madre en el momento en que Ismael reconoció la maternidad como distinta de sí mismo: 
Ismael, remotamente, se acordó de su propia madre. Quería acordarse. ... En realidad, lo único que cabía en ese ámbito donde quería ubicar de alguna manera a su madre, era Marta, alguna frase de Marta, algún gesto o simplemente el recuerdo (191).

El cuento infantil vuelve a asomarse a su conciencia por última vez, y él se da cuenta ahora de que tendrá que asumir el poder sobre su propio destino - que los errores hechos en el pasado forman parte de su existencia. Esta no ofrece origen absoluto, ni llegada final -una casa con una luz-, sino muchas oportunidades y muchas posibilidades vitales que se sucederán por el resto de su vida:

[9] La vieja que ocupaba aquel remoto lugar de su conciencia se reía de él, le decía que se había equivocado, que no había deseado las tres cosas elementales. ... (193).

De esta forma, en el último fragmento del cuento infantil, cuando ... se divisaban luces muy lejanas ... (194),

se refieren a las luces de la ciudad, experiencia concreta vital para Ismael. Asimismo se nota que las 'luces' siempre serán 'lejanas'. Los ideales no tienen una forma concreta, y siempre serán inalcanzables; no existen "las tres cosas elementales", y así, también, el hombre sigue equivocándose.

La mise en abyme que presenta el cuento infantil no es la única estructura especularia ofrecida en el relato. La sintaxis narrativa en su totalidad presenta una circularidad y un rigor de simetría que refleja una abismación notable, como se puede observar del siguiente esquema:

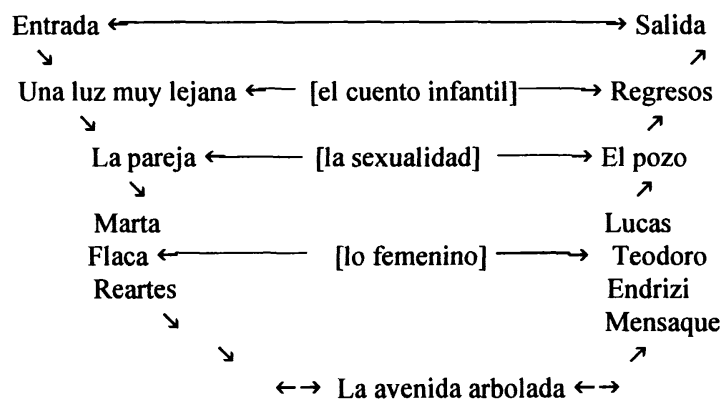

Algunos de los aspectos de esta estructura narrativa ya se han mencionado de paso; vale ahora recapitular y elaborar.

El segundo capítulo, "Una luz muy lejana", contiene los primeros cuatro fragmentos del cuento infantil, y sirve de introducción a la vida de Ismael - su llegada a la ciudad y la mudanza al patio, provocada por Eusebio, el mozo del bar donde Ismael trabaja de lavacopas. Así lo reconoce Ismael en "Regresos", el penúltimo capítulo: "Si entrar a la 
ciudad había sido como nacer, el bar podía ser perfectamente una infancia" (183). Este penúltimo capítulo sirve de etapa última a la trayectoria espiritual de Ismael, y contiene los últimos cuatro fragmentos del cuento; sirve como conciliación de todo lo vivido y reconocido por Ismael en sus años de aprendizaje. ${ }^{7}$ Constituiría el fin de la fase del espejo, con su identidad establecida, y su yo - hasta donde es posible - integrado, así como el comienzo de la fase edípica y su dominante relación masculina con el padre.

Existen dos capítulos que narran una crisis aguda en la configuración del 'yo' que será Ismael. El capítulo de "La avenida arbolada" —-el aborto sufrido por Marta—, como ya se ha mencionado, se ubica en el centro de la estructura novelística y contiene el quinto fragmento del cuento infantil. El capítulo antepenúltimo, "El pozo" —episodio del incesto de Flaca - contiene los fragmentos seis y siete y constituye el punto precisamente que le devela a Ismael la conciencia en cuanto a su identidad como ser humano masculino.

Investigación más profunda merecen el primer y el último capítulo de la obra "Entrada" y "Salida", respectivamente- por cuanto se reflejan uno en otro de forma casi idéntica, así dando la mayor contribución a la especularidad de la construcción. Dallenbach reconoce que la estructura circular es una forma de abismación que puede dar lugar a la conceptualización del círculo vicioso (37), un vaivén sin posibilidad de salir para progresar. De ahí que sean de gran importancia las diferencias que se pueden establecer entre estos dos capítulos, diferencias que permitirían una salida del círculo vicioso.

En las dos secciones, Ismael se encuentra contemplando la ciudad - y su vida en elladesde un punto externo. Puede decirse que aquí se presenta lo que Dallenbach llama una mise en abyme de la enunciación, en la que se "presentifica" (Dallenbach 100) el sujeto y el proceso de la producción enunciativa, así como el contexto que la condiciona (100, 223). La focalización de estos capítulos está centrada exclusivamente en Ismael, en sus reflexiones internas que, como prolepsis - "Entrada" - y analepsis — "Salida"- encierran los episodios de la fábula que retratan los seres humanos ahora asimilados en el ser propio de Ismael. Al mismo tiempo la reflexión circular de estos capítulos se puede considerar como mise en abyme transcendental, en cuanto trasciende el texto y refleja desde el principio del relato lo que lo origina, lo termina, lo funda y lo unifica (Dallenbach 131).

En la "Salida" Ismael se reconoce como ser autónomo, de existencia (que ya no de esencia) vital:

Se tocó el rostro. Habían pasado años, pero estaba, se sentía vivo (197, énfasis nuestro).

Enumera los otros “rostros", fragmentos de sí mismo que le han constituido esa experiencia vital:

Estaba solo allí, pero en la cabeza y en algún lugar de los ojos restallaban los rostros aquellos: Beatriz ("he rezado por usted"); Teodoro ("siempre hay tiempo para empezar de nuevo"); ... Marta ("te necesitaba en aquel momento, ..."); el perro ("Dios mío, por qué

\footnotetext{
${ }^{7}$ Aquí vale notar que entre el comienzo del relato y el capítulo "El pozo" han transcurrido unos diez años: en "Flaca" se menciona que ésta tiene dos hijos, de ocho y seis años (63); en "El pozo" el hijo idiota tiene "unos 17 años" (172).
} 
me has abandonado"); ... Chacón (“¿y? ¿venís o no?”); la Flaca (“usted es mi hermano, por eso lo he besado; puercos, inmundos, todos ustedes"); Jacinto ("es el único recuerdo que tengo y que voy a tener de él”) ... (197).

La diferencia más significativa entre los dos capítulos está en su último párrafo, que se citará a continuación:

$\mathrm{Y}$ de pronto una nube simuló ser un gigantesco perro que abarcaba con sus cuatro patas no sólo esa ciudad sino, hacia los horizontes, otras ciudades lejanas. El perro ladraba en los cielos y sus gritos llenaban el día y la noche distante. ("Entrada" 10)

En eso miró las nubes. Simulaban la forma de un perro negro y gigantesco que con sus cuatro patas cubría toda aquella ciudad y se extendía en los horizontes hacia ciudades lejanas. Parecía que el perro tenía adentro un grito contenido que, si salía, llenaría todo el espacio y no terminaría nunca. ("Salida" 199; última frase de la obra. Enfasis nuestro).

Es patente que la diferencia entre los fragmentos evita que el relato se sumerja en un círculo vicioso; lo convierte más bien en dialéctica. El grito (del perro) de la "Entrada" es como el del niño recién nacido (nótese que no se trata de 'ladrido'); el de la "Salida" es un grito contenido, es el grito del hombre que sufre las cosas del niño - y más- pero, como hombre, ha aprendido a sufrirlas en silencio. Al mismo tiempo señala el fracaso del proyecto del cuento infantil, en el que el hombre "rodaba tierra" para buscar con quién comunicarse sobre su vida: "podría hablar, decir que había salido a rodar tierra y que eso estaba haciendo" (11). ${ }^{8}$

En la "Entrada", Ismael se fija en "los monumentos de los héroes" (8) queriendo emularlos; en "Regresos", en el pueblo de Jacinto, encuentra un "monumento a la madre" (188). Desde el principio de su aventura se le indicaba la trayectoria de lo masculino (héroes) y al final se da cuenta de que los absolutos existen sólo como estatuas al pasado o en los valores abstractos (los mismos héroes, y La madre). La existencia concreta - como el espejo- ofrece fragmentación, dualidad, ambigüedad, dialéctica; de ahí que los "Regresos" sean múltiples. El grito contenido del perro de la "Salida" constituye, por tanto, el grito primordial, existencial, de todo ser humano consciente de sus propias limitaciones.

En Ismael se evidencia la madurez humana en la aceptación de sus propias debilidades y el reconocimiento de la imposibilidad de los absolutos y de corregir todas las injusticias - como lo hicieron los héroes y las madres. Permanece en él la lucha por conciliar la dialéctica entre el yo y el mundo, para poder vivir íntegramente. Ismael acepta su condición de hombre alienado --mirando siempre, en la "Entrada" y en la "Salida", desde afueracondición universal del ser humano y la que comienza en la transición del reconocimiento del 'yo' como entidad autónoma (fase del espejo), y del 'yo' como entidad social (Lacan 98). Acepta igualmente la ambigüedad del mundo; no hay absolutos. Tanto en la "Entrada" como en la "Salida" confirma que "... sólo Marta o Endrizi [padre de Beatriz] hubieran

${ }^{8}$ El grito de esos capítulos es de un perro, elemento temático de valor muy denso; se relaciona con el pozo (símbolo de ciudad, crisis, inmundicia), el cordero (sacrificio inocente) y con todas las injusticias del mundo (abandono, traición) cometidas hacia los impotentes (perro, Marta —el hijo abortado-, Flaca). 
bastado para llenar su existencia" (9). ${ }^{9}$ Es decir que en esa existencia Ismael acepta como clave la presencia de lo materno $y$ de lo paterno. Asimismo, la realidad, cuyo 'principio' regirá su existencia desde el término de la fase del espejo (Lacan 99), incluye en la existencia particular de Ismael a los Chacones, a la Flaca, a los perros abandonados y todo lo que la ciudad ofrece al ser contemporáneo. ${ }^{10}$ En este contexto Ismael tiene que establecer su yo, su origen, para poder concretar sus propios valores en su fase madura de ser socializado y en la consiguiente frustración permanente del ser humano.

\section{Obras Citadas}

Barufaldi, R., R. Boldori \& E. Castelli. Moyano, Di Benedetto, Cortázar. Rosario (Argentina): Ed. de la Revista “Crítica 68", 1968. 9-33.

Campbell, Joseph. The Hero with a Thousand Faces. 1949. 2nd ed., 1968. Princeton: Princeton University Press, Third Printing, 1973.

Clinton, Stephen T. "Daniel Moyano: The Search for Values in Contemporary Argentina", Kentucky Romance Quarterly, Vol. 25, (1978) 165-175.

Curutchet, J.C. "Crónica de la fundación de la novela cordobesa", Cuadernos Hispanoamericanos, 215 (1967) 405-410.

Dallenbach, Lucien. Le Récit speculaire. Essai sur la mise en abyme. París: Seuil, 1977. Eliade, Mircea. Mito y realidad. 1963. Madrid: Guadarrama, 1968. Traducción de Luis Gil [de Aspects du mythe].

Freedman, Alfred, MD. \& Harold I. Kaplan, MD (eds.) Comprehensive Textbook of Psychiatry. 2nd ed. 1967. Baltimore: The Williams \& Williams Co. [especialmente las páginas 275-282].

Jung, C. G. The Archetypes and the Collective Unconscious. 1959. 2nd ed. Princeton: Princeton University Press, 1968. Translated by R.F.C. Hull.

Lacan, Jacques. Ecrits. Paris: Seuil, 1966. [contiene artículos escritos entre 1939 y 1966].

Moyano, Daniel. Una luz muy lejana. Buenos Aires: Sudamericana, 1966.

\footnotetext{
9 En "Salida" reza: "habrían bastado" (197).

${ }^{10}$ Ver también Barufaldi, quien ve en la novela un mito de la ciudad, y Clinton, quien la ve como "a quest novel dealing with the search for moral and spiritual values within the context of modern Argentine society" (166).
} 
